\title{
Performance art temporalities: relationships between Museum, University and Theatre
}

Claudia Madeira, Daniela Salazar, Helia Marcal*

\begin{abstract}
This article addresses one of the leading challenging areas for those studying performance art today: its temporal dynamic, linked to the present, to the here and now. This temporal inscription is effectively at the core of the ontology of these pieces, which has repercussions in the relationship this art form has with the physical and conceptual spaces it occupies, and in the management of art collections that include them. Analysis of performance art temporalities will lead to a discussion of the spaces this genre has been occupying in artistic institutions. The values held by these spaces will be explored, and new ways of understanding them, especially in the relationship between university, museum and theatre will be proposed. This is the triad discussed by Jan Naderveen Pieterse in 1997 will serve as an analogy to reflect upon these issues. In this context, performance art pieces, artistic projects, and curatorial programmes from the Portuguese panorama will be presented as examples.
\end{abstract}

\section{Keywords}

performance art, museum, curatorship, theatre, transmission

\section{Introduction}

Performance art emerged in the 1960s, and it is still revolutionising the art world in unpredictable ways. This genre has been characterised by its ephemeral and event-like nature, which has been intrinsically linked to the context of its emergence. It is hard to point out what led to the expansion of performance art within the artistic community. Among the several factors that might have contributed to the emergence of this medium, four aspects seem to be particularly underlined in the relevant literature: (1) the growing tendency towards the dematerialization of the art object (see Lippard 1973), (2) the expansion of the notion of art as movement or action (which can be traced back to 
Pollock's action-painting - (see Kaprow 1958), (3) the use of the body as instrument (see Jones 2012), or (4) the socio-political context, linking the occurrence of performance art to a reaction against the art market, commodification and capitalism (see Goldberg 2001 or Bishop 2012). The notion of performance art has since expanded, incorporating various peripheral art forms that do not fit specific categories within the realms of visual or performing arts (see Jones 2012 or Madeira 2017). Both the ephemerality of the medium and the lack of categorisation of an expanded field that became known as performance art has delayed possible incursions on the preservation of this genre, which only became noticeable in the mid-1990s. Again, there were several aspects associated with this tendency. A strong nostalgic response regarding performances held in the $1960 \mathrm{~s}$ emerged, leading to a "process of historicization" of these works. According to the historian Jessica Chalmers, the idea that these works were presented with a clear intent against commodification and in favour of an absolute ephemerality led to a resurrection of this works into "art history" and its re-performance "as a generational legacy" (Chalmers 2008). The museum, along with the Academia, was one of the first places where this historicization was somehow made. A consequence of this growing tendency of performance art acceptance inside the museum space was the occurrence of multiple performance presentations and re-enactments of past events held since then (see Jones 2012a), and the recent incorporation of performance art in museum collections (Calonje 2014, Laurenson and Saaze 2014). Although it makes sense that museums could be the precursors of performance art conservation, the place of this artistic genre inside these institutions is constricted and undefined. That happens perhaps because performance art itself lacks a specific ontological definition, but it could also be that practices of preservation are also bounded by specific disciplinary borders and procedures that do not resonate with the variability and variety of this artistic genre. At the same time, performance art preservation is becoming increasingly urgent. Seminal artworks created between the 1960s and the mid-1980s suffer from an apparent deficiency of documents and material remains, which aggravates the absence of memories caused either by the fragmentary condition of memory or by the disappearance of key-actors that produced or participated in those art events. Recovering these performance artworks is especially onerous in the case of manifestations that operate outside the art market circuit, or that 
were created as a subversive response to a context of oppression. That is the case of most performance artworks produced throughout the world during that period, which witnessed the rise of the social ruptures and affirmation movements, with issues ranging race discrimination, LGBT rights or AIDS awareness, gender, among others. Among the social ruptures and convolutions it seems particularly relevant to mention the occurrence of several military operations, namely the Vietnam War (1955-1975) or the Portuguese Revolution, and the Colonial War (1961-1974), or the advent of socio-political changes, which specifically in Latin America, Eastern Europe, or in the Iberian Peninsula produced many artistic manifestations across the fields of visual and performing arts. This paper aims at discussing the preservation of performance art, focusing specifically on three main issues: (1) performance art ontology and the possible futures of its manifestations, i.e. in which ways can these works be preserved; (2) what is the place of this genre in artistic institutions, i.e. what are the places in currently occupies, and how that occupation could be expanded into the realm of the museum; and (3) how performance art's futures can be potentiated within an institutional context. To develop this argument, the notion of preservation will be grounded on three different spheres: historical, conservation, and curatorial. Examples from the Portuguese performance art panorama, in the form performance art pieces created during and after the Portuguese Dictatorship, as well as artistic and curatorial projects, will illustrate this theoretical inquiry.

\section{The non-history of Portuguese performance art}

The first Portuguese happening, at least the first called as such, occurred in 1965 at the now-extinct Galeria Divulgação (Lisbon). The history of Portuguese performance art has, however, only started to gain track in the millennium and still lacks completion. Although this statement could be applied to all "art history" in the sense that there are no "completed" art Histories, it is particularly appropriate here as these practices have not been transmitted as art to new generations either in the field of the arts or Academia. This statement is neither new nor exaggerated. Art theorist, artist, curator, and critic Ernesto de Sousa (1921-1988), one of the participants in this particular history, both as a creator questioning the concepts or as a mediator up to the 1980s, remarked as follows on the Portuguese "vanguards", which naturally included performance art: 


\begin{abstract}
"the history of modern Portuguese culture is (still) a history without history, with no real internal evolution, without continuity. (...) The history of the avant-garde in Portugal is the history of an absence where asceticism and the senselessly heroic are mixed with an inevitable epigonism, and the rest - in the best cases - are of no importance. Following its logical meanderings is to collect the parts (only parts are possible) of a huge future patience" (Sousa 1998, 134-135).
\end{abstract}

The Portuguese socio-political context provided special conditions for the appearance and rapid disappearance of this genre. Portugal suffered one of the most prolonged dictatorship periods of the 20th century (1933-1974), which was characterised by massive political persecution and repression, as well as, a high degree of illiteracy and poverty. Many of the works produced in Portugal until the mid-1980s dealt with Portuguese social performance issues (through themes inherent to the Revolution of 1974 or the Dictatorship, and Colonial War - 1961-1974, for example) (Madeira 2007, 2016, 2017), a factor that cannot be ignored when thinking about the absence of records and documentation that led to their early invisibility. Works such as Música Negativa (Negative Music - 1965), by E. M. de Melo e Castro, Identificacíon (Identification 1975) by Manoel Barbosa, Rotura (Rupture - 1977) by Ana Hatherly (1929-2015), or o pombal (The dovecot -1973 ), os dias cinzentos (The grey days - 1981) by Carlos Nogueira, or Revolution my body nr.2 (1977), by Ernesto de Sousa, are some examples of those works.

The ephemeral character of Portuguese performance works was enhanced by the lack of means or will to archive or record the performance events. On the other hand, the organisation of the performance events was also somewhat informal, with the emergence of performance art in Portugal being mainly characterised by the networks that were set up between artists in Portugal and abroad, through numerous prepared performances, spontaneous actions, festivals, among many other artistic formats. These actions, events, rituals or happenings (the terminology is very diffuse, even for the artists themselves), predominantly emerged before the art market. With the revival of the Portuguese art market during the mid-1980s, a process coinciding with a progressive democratization of Portuguese society that diminished art's function as a means of protest, the artists' paths were diverted into other professional activities or even other media linked to the market, such as painting or sculpture, losing track of the performative practice of the works from their past (Madeira 2007, 2016, 2017). Considering, however, the precarious condition of 
the memory of these events - which mostly exists in the minds of artists or witnesses that are rapidly disappearing, what remains of this story and how can we recover it and transmit it, to enhancing the possible futures of these works? Before answering this question, it is important to discuss which kind of futures can be expected for these works. As mentioned above, performance art emerged as a reaction to the art market and institutional power. Can these actions ever be preserved in those contexts? Is it even possible to speak about the survival of performance art for future generations?

\section{On the anachronic relationship between the performance event and the after-the-fact}

Back in 1993, the Performance Studies theorist Peggy Phelan, departing from a Lacanian and Derridean analysis, characterised performance art's ontology as follows (pp. 146):

Performance's only life is in the present. Performance cannot be saved, recorded, documented, or otherwise participate in the circulation of representations of representations: once it does so, it becomes something other than performance.

This definition has unclear and complicated consequences in the understanding of the past and future of performance art. After all, if performance art has neither past nor future, how is it that past performance events have come down to us? In the text where Peggy Phelan puts forward the idea of performance art's sole existence in the present time, the author describes Angelika Festa's 1987 piece, Untitled Dance (with fish and others). Is a description not a way of bringing the past into the present, and of transmitting it into the future?

Looking closely at Peggy Phelan's remarks it is possible to see that the key issue to address in this discussion is actually beyond the traditional opposition between performance art and its possible futures. This author states that performance art exists only in the present as any other existence is dependent on "the circulation of representations of representations" (Phelan 1993, 146). This mise en abyme is central in Phelan's theory - in the same text this author puts forward this construction about performance art ontology, this author also refers that representation "reproduces the Other as the Same" (Phelan 1993, 3). In this sense, Phelan adds, the "relationship between the real and the representational, between the looker and the given to be seen, is a version of the relation between self and other" (3). This dialectic encounter is 
nonetheless perpetuated as Same in the several reproductions of representations that populate the performance art event after-the-fact. In this case, Phelan's account on performance art ontology needs to be seen as opposition to fixed and static representational modes, which obey to the oppressive and patriarchal logic of the archive.

Performance art is then not fundamentally contrary to its perpetuation in time; indeed, it opposes to how its preservation operates and is operated by forms of representation. In this sense, performance art objects its documentation since documentation is a representation of the performance event. Looking at recent advances in post-structuralist theory, especially regarding works by J. L. Austin and Jacques Derrida, which crucial for the field of Performance Studies, it is possible, however, to consider that both the performance event and its future instances are performative. These future instances can be either documents or even re-enactments. Theories about representation or performance art ontology have emerged since these theoretical explorations. In this sense, the works of Philip Auslander and Amelia Jones are especially relevant $^{1}$.

Philip Auslander, drawing from J. L. Austin's seminal work "How to do things with words?" (1969), develops in The Performativity of Performance Documentation (2006), among other texts, an argument opposing Phelan's remarks on performance art ontology. There are two main pillars of his line of reasoning in The Performativity of Performance Documentation: (1) performance art, instead of existing solely in the present, might only be considered as such in the moment of its (photographic) documentation (Auslander 2006) and (2) any act of performance documentation is performative a priori, as "the act of documenting an event as a performance is what constitutes it as such" (Auslander 2006, 3). Documentation then works as a complement to the performance work. Auslander's reasoning clarifies that the relationship between the photographic document and the moment of its creation (the performance event) provides meaning to the document itself. This meaning is, however, not necessarily attached to its evidentiary nature, but to the intention of its creation - as a document of a performance event. The intertwining between performance art and its documentation is

\footnotetext{
${ }^{1}$ It is important to mention that these authors' perspectives come from the fields of Visual Culture (Auslander) and (Art History). Other important authors such as Judith Butler, whose work departs from a linguistics perspective (namely from Jacques Derrida's and Gilles Deleuze's work) are not referred in this exploration.
} 
also proposed by Jones. The art historian, Amelia Jones argument, does not discuss the nature of the photographic document as validation of the performance event. This author, nonetheless, refers the "mutual supplementarity" of this genre and possible photographic documents, adding that "while the experience of viewing a photograph and reading a text is clearly different from that of sitting in a small room watching an artist perform, neither has a privileged relationship to the historical 'truth' of the performance" (Jones 1997, 11). These views necessarily imply that neither the originary event is more truthful to the artwork than its documentation, nor is performance art documentation trying to provide a full or uncontested view of the performance art event. The document serves as medium for a dialogue to happen between the past and the present, within a given context, for a given referent. Documents are, for that reason, truthful enough to be the anchor of future performative interpretations of the performance work. Indeed, for both Auslander and Jones, both the performance event and the documentation, or possible re-enactments, are contingent, mediated and fragmentary. Their views mimic the idea of absence of representation developed by Jacques Derrida (1977), who suggests that there is no outside-the-text - everything that we grasp is text, which can only be partly read, according to a given referent. This perspective is a crucial point of the current discussion: performance art's futures imply that performance art cannot be a representation of representations. If performance art events are understood according to that given referent, what distances the event from its documentation or future instantiation? Like the documentation of the performance event, the event itself is confirmed or read by the reception of a spectator at the moment of its actual or simulated instantiation. When it occurs in the presence of someone, when it is only transmitted through someone, or even through a recording machine, this performance gains repercussions in the memory of these individuals - who experience it either through the event or its documentation. For that reason, it is always mediated and fragmentary. For that reason, it is always a product of construction, either physical or not. And, for those reasons, the performance art event is, along with its documentation, a text, always partially apprehended. Through these mediation processes, of which the performance art event is at the centre, performance art becomes itself through several instantiations in its history. This perspective implies that performance art is not necessarily linked with the originary (or inaugural) event: that link 
exists since the originary event consists the first instantiation of the artwork, and thus, the point of departure of its plural authenticities. Looking back at Phelan's account, performance art does not exist solely in the present. In this sense, performance art not only exists outside the present time, but survives in its uncontained plurality.

This notion echoes the idea of artworks' biography explored by the philosopher Renée van de Vall and co-authors in 2011. Thinking about artworks' biography means to accept artworks' changeability and acknowledging that change can happen with time and be induced by the interaction between the artwork and several actors (Vall et al. 2011). The notion of biography is especially important because it "enables us to identify and compare stages and turning points in artworks' lives" (Vall et al. 2011, 6). Thinking about the case of performance art and its afterlives, it is possible to see documents or reenactments as instances of the artwork's biography - turning points that can enhance change in the meaning and materialisation of the artwork without compromising its authenticity, which is, in turn, necessarily plural, made out of viral possibilities (Bedford 2012) or forms of text. In this sense, performance art's afterlives can be seen as memory devices that can be expressed, as the theorist Louis van den Hengel puts it, "through particular bodies and individuals", and yet, "cannot be contained in any single place but rather operates by way of affective interconnections or creative encounters". In this case, memory itself "works as a performative practice" (Hengel 2017, 127).

Just as living beings that survive in a given habitat, just as artworks that have lives and afterlives, it is of utmost importance to understand what are the habitats that allow performance art to grow, or to its memory to develop as performative practice. In this sense, it is particularly relevant to see which are the places performance art currently occupies and how that affects its historicization in and as practice.

\section{Anarchic occupations: the spaces of performance art}

There are many spaces performance art (possibly infinite) may and has been occupying. It is in these places of memories that short stories about the genre can gain relevance, visibility, and history, thus making it part of the past, present, and future cycle we discussed earlier. In fact, as noted earlier, the worst threat to the future of performance art is the expiration of its present. These places are, then, activators, or perhaps even catalysts, of the performative practice of these works. The very expression may occupy 
reflects one of the problems of the spaces of performance art: performance art and its memories occupy many different spaces within the public sphere, from museums to the streets $^{2}$, universities, or even theatres and their stages. Sometimes modest, other times visible, performance art's presence has become common in these spaces, and yet, it seems that this art genre is always surviving, not because, but despite the environment.

The exhibition Teatro sem Teatro (Theatre without Theatre), commissioned by the Museum of Contemporary Art in Barcelona in 2007, and presented also at the Berardo Collection Museum between 2007 and 2008, is an example of the presence of performance art (or, at least their memories) in the Portuguese museum context. This exhibition included some, though few, pieces by Portuguese artists such as José de Almada Negreiros (1893-1970) - Manifesto Anti-Dantas (printed document, 1915), Helena Almeida (b. 1934) - Estudo para 2 Espaços (photographic documents, 1977), or Ernesto de Sousa (1921-1988) - Revolution my body nr.1 (photographic documents and text, 1977), mainly consisting on the presentation of the performance artworks' material remains. Despite envisioning to propose a theatre without theatricality, no performances or re-performances were held neither at Lisbon's exhibition nor Barcelona's. It almost seemed that Theatre without Theatre was also Performance without Performance.

This case is paradigmatic of an absence of practices to deal with performance art in museums, both at a conservation and a curatorial level. It illustrates a tendency in museums worldwide, which only now is starting to be reversed especially due to pioneer efforts by a few international museums and galleries ${ }^{3}$. Although museums started to collect performance artworks since the advent of the new millennium (Wheeler 2003), many times acquisition implied and still implies the incorporation of the material remains of these performances (Calonje 2015, Laurenson and Saaze 2014, Marçal 2017b). And nowadays, even with a growing number of performance artworks being acquired by institutions (Calonje 2015), there are still some problems with their incorporation. Documentation is often considered an incomplete process that cannot truly capture the

\footnotetext{
2 The discussion of performance art as public art and in streets, although pertinent, falls beyond the scope of this paper. For more on this subject please consult, for example, Radical Street Performance: An International Anthology, edited by Jan Cohen-Cruz (London and New York: Routledge, 1998).

${ }^{3}$ Tate London, for example, has been collecting performance art, and intensively researching about how to preserve and present these artworks. Their focus tends to be, however, in delegated performances (Bishop 2012), or performances that do not rely on the artist's presence.
} 
event (Marçal and Macedo 2017). Re-enactments are often seen as appropriations ${ }^{4}$, or as institutional devices lacking authenticity. As referred by Hal Foster in his most recent work $(2015,127)$ the multiplicity and convergence of temporal units in re-enactments, instead of working the memories of performance art, might imply a dissociation between the artwork and its own time:

Not quite live, not quite dead, (...) reenactments have introduced a zombie time into [museums]. Sometimes this hybrid temporality, neither present nor past, takes on a gray tonality, not unlike that of the old photographs on which the reenactments are often based, and like these photos the events seem both real and unreal, documentary and fictive.

Re-enactments are, however, considered by many theorists as a way to restore the performative and material practice of the artwork (see Hengel 2017, for example). One of the most prominent Performance Studies theorist, Rebecca Schneider, even refers to reenactments as acts of survival, that "may be a critical mode of remaining, as well as a mode of remaining critical: passing on, staying alive, in order to pass on the past as past, not, indeed, as (only) present" $(2011,7)$. In other words, re-enactments serve not only to restore the practice and embodiment of these works but are also mechanisms to reflect upon the history of the works itself critically. In this sense, is it possible to think about reenactments in the museum context as a way to pass the memory to future generations?

There are four main identifiable obstacles to performing re-enactments of historical performances inside the museum sphere. (1) The first lies with the originary context of artworks such as the ones referred above. Museums tend to consider that artworks created between the 1960s and the mid-1980s, by opposition to what Claire Bishop regards as delegated performances (2012), are primarily against commodification, mainly resisting any means of perpetuation. (2) As referred by Laurenson and Saaze (2014) regarding the works of Tino Sehgal, restoring the performative practice of performance art requires maintaining a network of knowledge and actors, which can quickly become unsustainable for small to medium-sized institutions. (3) Many of the actors that were present in the first instantiation of the works are now deceased, and

\footnotetext{
${ }^{4}$ Regarding the documentation of Marina Abramović's Seven Easy Pieces, for example, a work where the artist re-enacted five works from other artists, R. Blackson considers it a possible act of appropriation that could ultimately jeopardize the authenticity of the re-enacted works. He states that it challenged and reassigned "the authorial agency of the (re) performed works", and that the artist "has taken steps to potentially eclipse the works she re-enacted in Seven Easy Pieces by meticulously documenting each of her performances" (Blackson 2007, 39).
} 
recovering the details of the artworks becomes more and more complicated. That is the case, for example, of Ernesto de Sousa, which seminal performance and mixed-media works, such as Luís Vaz 73 (1975), remain incomplete due to the lack of information ${ }^{5}$ (see Marçal et al. 2017). (4) At least in Portugal, to this time there was no collaborative effort to join the dispersed information about Portuguese Performance Art. Material remains from performance artworks as well as related information are spread around several Portuguese museums and private collections, most of which do not dialogue or carry out joint projects with each other. The scattered nature of these collections is seen not only geographically, but also regarding categorisation: traces of these artistic practices are to be found in museums of modern and contemporary art, as well as in performing arts museums, or even in ethnographic or history museums ${ }^{6}$. Moreover, Portuguese performance artworks are absent from Portuguese museum collections, which is another impediment to the practice of re-enactments of to their effective preservation. Besides re-enactments, there are other obstructions to performance art incorporation that lie in the policies of acquisition, management, and conservation. These practices of preservation are essentially material-oriented, creating many issues when these works indeed arrive at a museum collection. How to manage the inventory of artwork that does not exist? Or, how to curate the inconceivably large volume of information that comes with the documentation of a performance artwork?

Several projects have emerged in the last years to try to answer these questions. Collecting the Performative: A Research Network Examining Emerging Practice for Collecting and Conserving Performance-Based Art (2012-2014), and Performance at Tate: Collecting, Archiving and Sharing Performance and the Performative (2014-2016) are two of the main research projects aiming at finding solutions to these problems. Both emerged as collaborations between the TATE Galleries and the academia (Maastricht University and University of Exeter, respectively) and their results are now starting to

\footnotetext{
${ }^{5}$ In the catalogue of the exhibition Anos 70: Atravessar Fronteiras (1970s: Crossing Borders), the curators A. Ruivo and R. H. da Silva discuss the difficulties of presenting Luís Vaz 73. See Ruivo 2009, Marçal et al. 2017 for more details. This exhibition presented many performance artworks. Besides Luís Vaz 73, however, no performance artworks were showed as performance.

${ }^{6}$ Here, we must not forget that performance art practice is intimately linked, in various ways, to the social performance and is often a resource in the research and transmission of these contexts and social, political and cultural conjunctures (Madeira 2012, 2016, 2017).
} 
become available. One of the main results of the first project is the Live List, which features some aspects to have in consideration when collecting Live Art (Tate 2014).

The collaboration between art institutions and the academia is also visible in Portugal, where the first project aiming at conserving contemporary art by Portuguese artists (Documentação de Arte Contemporânea) started in 2009. PO.EX project (70-80 Arquivo Digital da Literatura Experimental Portuguesa) created the first digital archive for experimental literature by Portuguese poets, including some performance works emerging from this lineage. Despite the best intentions to reflect upon this theme (initiated in the 1980s by Isabel Carlos from Centro de Arte Moderna - Calouste Gulbenkian Foundation), academic research about Portuguese performance art and its history only emerged in the mid-2000s in the form of Master or PhD Dissertations (Metello 2007, Madeira 2007, respectively). The lack of recognition of this genre and its history in art history or related courses and degrees might be to blame regarding the delayed answer to this problem by the academia. This is noticeable not only in University programs but also in course curriculums, where the presence of contents from Performance Studies is merely occasional ${ }^{7}$.

The same also happens in theatre courses, where the practice and history of performance are only broadly referred. And while some theatre laboratories are experimenting with what could be understood as performance art (or, somehow, an expanded theatre), academic institutions are still reticent in developing Bachelor or Master programs that equally explore theatre and performance. The Portuguese Academic panorama contrasts with the variety of programs that are thriving in the international context, where courses in Performance Studies or Theatre and Performance populate Universities in the West. The Portuguese setting, along with the absence of Research Centres focused on Performance Art, leads to the lack of regular funding for the study of these artworks. The rigidity of the academia is also contrary to the tendency that is being observed in theatres across the country.

Discontinuity is the central aspect to highlight regarding theatres in Portugal while some theatres present programmes with some instances of performance art there is

\footnotetext{
${ }^{7}$ One important exception is the newly formed post-graduate course in Performance by the Faculty of Fine Arts from Porto University.
} 
no specific space where this art genre is fostered and developed. Some of these small and yet seminal instances are, however, worth exploring. Although these initiatives are dispersed throughout the country and several venues, Maria Matos Theatre (Lisbon) ${ }^{8}$ has become an example due to its very diverse programme, with contributions by many Portuguese performance artists (such as the duo Ana Borralho \& João Galante). These artists tend to belong to a younger generation that is recovering performance art as an artistic medium while experimenting with different formats, using, for example, video installations to expand the visuality of their works, or working with community engagement through workshops, pursuing a model of the above-mentioned delegated performances. One of the problems that emerge with this format, however, lies with the focus on newly constructed performance artworks. Theatres are naturally eager to explore the limits of artistic creation within and outside the realm of what is considered Theatre (which boundaries are slightly blurred). It is not part of Theatre's mission to preserve artworks for future generations, which might explain the timid expression of reenactments in these spaces, and the absence of documentation of these artistic practices.

The absence of documentation of these embodied practices will make future preservation efforts especially challenging. In the rare occasions Theatres or independent (or alternative) spaces perform re-enactments, these absences are even more dramatic, as they denote the deficient intergenerational transmission of important testimonies. Zé dos Bois Gallery (ZDB, Lisbon), for example, was the stage of an artistic re-enactment. In this case, the first so-called happening, mentioned at the beginning of this paper, was reenacted in 2017, in the context a programme featuring many works of experimental poetry. Several interviews with relevant actors, many of whom are mature, where conducted by the curator Natcho Checa. This was an excellent chance to gain knowledge about this seminal event in Portugal's history, and the conditions of this assessment will

\footnotetext{
${ }^{8}$ Other cultural centres, which do not qualify as theatres, are also worth mentioning: Culturgest, which has been exploring theatre's formal frontiers with many events in their agenda. The show Enquanto Vivermos, for example, created by Pedro Gil (July 2012), explored the idea of script and the impossibility of repeating actions by showing a video recording of a past performance while performing the same action. Calouste Gulbenkian Foundation was also a hub of artistic exploration in the 1980s with the ACARTE (see Vieira 2014 for more details). As referred by Madeira (2007, 2012), the generation that followed ACARTE, more inclined to what has been called new dance, did not recognised the early generations of performance artists nor their artworks, mostly due to an absence of inscription of these early experiments in art history. Alkantara festival also explored other artistic formats very much associated with performance art. These institutional explorations are, however, inasmuch as what happens with Maria Matos Theatre, more focused in new creations, instead of historical or artistic re-enactments, among other devices for remembering past artworks.
} 
probably be difficult to recover in any future efforts. These irretrievable and vital testimonies where, however, never published nor released as raw data. Later on, it became evident through personal communication that these accounts were not registered $^{9}$. The reasons for this situation are difficult to identify at this moment. Given this case, it is possible to argue that a symbiotic dynamic between this institution and the academia could provide the means to document those precious accounts. A collaboration with a Museum could also have changed this outcome. The practices of preservation of ZDB focused more in the transient materialities of the bodies that performed that happening. In which ways could these practices be expanded?

The mission to preserve this Cultural Heritage is commonly associated with museums which, for the reasons mentioned above, have difficulties dealing with these works. The experimentation inherently related to the Theatre space would ideally be transferred to the Museum. The capability of recovering traces and building an archive of these practices, a skill much associated to the Academia, could also be somehow retrieved by Theatres, which, in turn, have a privileged access to artists throughout crucial moments of their practice, namely technical visits, technical and general rehearsals, or discussions with lighting and scenography technicians. Being conscientious of the limits of each of these institutions, we may find some answers and alternatives if we conceive a hybrid space, a liminal space of in-betweeness where Museums, Universities, and Theatres could mingle and, ideally, thrive. Can the Museums be transformed into laboratories for experimentation, where embodied practices are lifted above normative views about of the truth of a given artistic object?

\section{Institutional hybridity as means for performance art continuity}

In his article, Multiculturalism and Museums - Discourse about the Others in the Age of Globalization, Jan Naderveen Pieterse raises questions about multiculturalism that could also be asked about performance art. Continuing this analogy, Portuguese performance art, and somehow Performance Art, in general, could even be seen as an Other in the Art World, as it was complicated for this genre to be represented in museum collections or inscribed in art history.

\footnotetext{
${ }^{9}$ Claudia Madeira and Natcho Checa, personal communication, March 2017.
} 
In his analysis, which is mainly focused on Ethnographic Museums, Jan Pieterse puts the Museum at the centre of the Western Civilization. This author compares these structures with artistic or historical museums, referring that Ethnographic Museums have a certain ambiguity, being politically peripheral while holding a high symbolic value. This framework, therefore, allows for an emergence of dominated and peripheral discourses, leading to reflexive approaches to the Other. In this sense, Museums have the potential of becoming places of civic engagement, with exhibitions working as laboratories. Museums can thus become spaces of transformation.

In a globalised era of information, this author refers that previously self-contained categories of the Self and the Other are now fragmented in several Others. This cultural change necessarily implies a different way of seeing and acknowledging these many Others. Aiming to identify strategies to promote a reflexive representation, Pieterse questions which institutions should serve as a model for the Museums. In this inquiry, this author presents two alternatives: University and the Theatre. In a way, by proposing these two options, this author ends up introducing a triad, University-Museum-Theatre, which answers to many of the problems of Performance art's practices of preservation.

Referring to Gurin (1991), who believed that producing an exhibition was more like creating a play than any other form, and to Harris (1990), who said that museums could be places where the university and the theatre meet, Pieterse suggests that Museums could be mediators, being at the centre of the discussion and potentiating institutional encounters.

Thinking about this triad in the specific case of Performance Art allows us to say that the University (as it is a space for personal and academic development, research and experimentation) is inevitably linked to the Museum, where this analysis is based on historical Heritage, and on the Theatre, where the transmission-experimentation gains a body, and recovers embodied memories. In this sense, the future of performance art is based on a theoretical-practical knowledge that is closely related to academia. They are, moreover, materialised through archives, established in critical repositories, constituted through the accumulation of knowledge that is articulated, sometimes through an expository component, with the museum. Furthermore, they are still transmitted- 
experienced as (re)embedded experience, which leads to re-enactments or new performances.

This triad has characteristics that promise to empower not only the future of these more subaltern genres in museums but also new ways of life in these spaces. But it also presents some problems. On the one hand, the establishment of a performance art archive promises to be a Herculean task, mainly because there are no public entities that can guarantee its sustainability. It is also difficult to ensure the means for such an extensive archive, and a significant issue is the deciding of what actually should be archived, bearing in mind that most theorists do not agree if it is even possible to store or document performance art. Above all, it is difficult to define what kind of documents to file and, more importantly, when and where to stop. Besides this, the fact it is a relatively recent art form brings some problems regarding preserving works. This factor is becoming particularly problematic because artists and other participants are disappearing and with them their memories, the essential basis for academically reconstituting the various performance stories. In the transition from the materiality of the documents and testimonies available for a materiality of a body which transmits and experiments (or the Museum-Theatre dichotomy), we are trying to guarantee the transmission of the repertoire of these works.

With the resurgence in Portugal of a new cycle of performance art at the dawn of the new millennium (Madeira 2012, 2016), there have been artistic projects incorporating a number of these aspects. In Porto, for example, A Sala (The Room) (2007) explores the dichotomy private-public, by presenting performance artworks in the living room of António Lago and Dr. Susana Chiocca (PhD in Performance Studies). In this project, the artists shared their personal space with anyone wanting to present performances (from various disciplines and generations), also creating space for the possibility of reenactments, namely, performers from the 1960-1980 generation. However, neither the academic nor museological component was introduced here. In 2009, one year after the exhibition Theatre without Theatre, Berardo Collection Museum presented one of Ernesto de Sousa's works, Revolution my body nr. 2 (1981), in the exhibition Arriscar o Real, curated by Larys Frogier. This Museum provided publics with a participative celebration of Ernesto de Sousa's work, presenting them with a set of instructions written 
by the artist, to be performed in the Museum space. At Serralves Museum (Porto), the programme Museum as Performance, which is it its third edition, is another example of an emergent and relatively new initiative that is pushing the borders of the Museum's mission. Different artistic projects, created by artists from all over the world, are performed inside the Museum space throughout a weekend each September. This program has emerged with the intent of recovering the memory of this institution as a performative space. The actual consequence of this project lies, however, in the opportunity for artists to present their new creations. All selected artworks, nonetheless, verse on the idea of the Museum as a performative space. The Museum space is, similarly, expanded, as it is not restrained by the museum walls, also operating in the outstanding gardens that frame the award-winning building.

Besides Maria Matos Theatre, other spaces in Portugal's capital have felt a growing need of hosting performance artworks, sometimes even trying to create a nostalgic atmosphere while recalling events from the past. Project P! Festival, which occurred in Lisbon (11-14 April 2016), is illustrative of this tendency. Produced by the São Luiz Theatre and National Museum of Contemporary Art (MNAC - Museu do Chiado), and commissioned by Ana Pais, this intensive festival emerged as a celebration of the centenary of what is now being considered the first Portuguese Performance artwork - the Futurist Conference by Almada Negreiros (1917). This project is especially relevant as it has become not only a celebration of the past action but also a restoration of the performative space of the São Luiz Theatre. Originally called Teatro da República, São Luiz was the space where the Futurist Conference was presented by Almada Negreiros. By offering different artistic approaches to the Futurist Conference, which involved a wide variety of media besides the performative body of performers, Project P! recovered more than the function and history of a given space, within a given place, or than the performative enunciation of the Futurist Conference. By allowing several artists to use the Futurist Conference as a starting point rather than an end in itself, Project P! fostered the development of several ramifications of the Futurist Conference beyond its format, its themes, or its own time.

Among the artistic ventures present at Project P!, the project REACTING TO TIME: The Portuguese in performance art, by the choreographer Vânia Rovisco, deserves 
a special mention. Aiming at recovering the physical memory of Portuguese performance art, and having a specific focus on early experimentations with this medium, this project appeared precisely as an attempt to create this hybrid space in artistic re-enactments. Drawing from the dance and performance studies theorist André Lepecki's notion of body-archive (Lepecki 2010), Rovisco considers that bodies have an incorporated knowledge and that ignoring such a source, 'which comes from a relation of accumulated reflexive cultural actions (...) is a flaw in the recognition of a heritage that belongs to all of us' (AADK 2016). In the absence of an archive, Rovisco collects the memories of artists, which are embedded in their words and performative practice (i.e. their bodies), transmitting them through her own body. She does so by transferring this corporeal knowledge to an undetermined number of workshop participants, over an entire week. The workshop participants, who do not need any previous knowledge or dance practice, engage in the process of transmission by embodying the gestures and the score and by, at the end of the week, presenting the performance work in a given venue. This process not only transports the memories of the artwork into contemporaneity through their actualisation (Lepecki 2010) but, with the work's presentation, it also engages in a conversation between the artist's generation and their legacy (Marçal 2017a). According to Rovisco, more that transmitting the specific gestures that constitute the performance artwork, she trains the bodies to understand the work's temporalities. What she aims at transmitting is not necessarily the work as it was, but the spirit it embodied, the tension it created, the disruption it generated (Rovisco 2016).

Through this process, Vânia Rovisco's choreography seeks (and finds) a hybrid sphere within the various spaces it ends up occupying. Its first transmission occurred at the Arpad Szenes Vieira da Silva Museum, a fine-art's museum. Its fourth transmission has held in Casa Negra - AADK Centre, an alternative and experimental gallery in Spain. In the context of Project P!, Rovisco co-directed a re-enactment of an artwork by Fernando Aguiar at the National Museum of Contemporary Art. Seated in the grey stairs of the museum's lobby there was the artist Fernando Aguiar, looking at the past of his own action in the present. In rethinking an artistic re-enactment process through a transmission lens, Rovisco explores the exhibition or presentation space, like a laboratory where there are learning processes both in the history of Portuguese performance art, as 
well as in the experimentation with the performative body of the past. Artworks are transmitted through documents and transmission-experimentation processes, which perpetuate forms of embodied knowledge, transforming somewhat phantasmagorical works into collective memory. In this process, the museum also becomes a place where new ways of managing, thinking, and exhibiting this art form arise.

\section{Futures of performance art: conflicts between space and time}

Performance art temporalities are still not consensual. The struggle between the times (past, present and future) of this artistic form and its venues (university, museum, theatre) is at the heart of the discussion about documentation, preservation, transmission and mediation of performance art. Above all, this debate, as well as the argument developed in this article, appears as a conflict between opposing forces connected to the same object.

In thinking about performance art times and venues in the context of the university-museum-theatre relationship, it is possible to insert questions of identity in this field; in other words, the right of expression, visibility, alterity and preservation of a history. A multicultural form is needed in preserving performance art - a relentless quest for multiple narratives and perspectives on performance artworks. Only through this multiplicity, through the abundance of physical and embodied instantiations, of testimonies and witnesses, will it be possible to transmit these works to future generations. On the other hand, besides these political, cultural and social questions, we could enumerate a set of others that arise through the actual process of institutionalising these memories, materials and practices. If in the context of the university, the knowledge built, as far as Portuguese performance is concerned, is still dispersed among different researchers and perspectives, perhaps due to the absence of a place for joint discussion, we can deduce that is not always so in the case of a museum or theatre complementary policy or programming. In the case of the Portuguese museum, there is no institution claiming it is the entity to house a Portuguese performance art archive.

There are many problems surrounding the transmission of this cultural heritage in the Museum, which could be complemented by a programme in partnership with theatres and universities. This perspective presents opportunities regarding managing and curating this art genre, but it also offers some challenges. By looking for new and different views 
about these works, complying with a multiculturalist perspective of performance art and its (hi)stories, fresh, innovative, and inclusive exhibitions take form; however, the resources needed to research and develop (and, thus, store) this information quickly becomes unmanageable. At the same time, the communication strategy between the Museum and performance artists could be compromised by the involvement of many other actors from Theatres and Universities, leading to an increase of the time spent in the preparation of the exhibition. Also, as Museums usually lack the space to promote reperformances or activations of performance remains, there is a need to amplify the scope of this institution, leading to a necessarily straight collaboration between Museums and Theatres, two organizations with different missions and thus styles of leadership. Regarding the relationship between these two institutions and the academic world, the primary challenge comes from funding strategies, as Museums and Theatres usually have resources directly allocated to the exhibition/presentation of manifestations of Cultural Heritage, while Universities have to find external funding to participate in this venture.

Besides these operative challenges, it is clear that this triad shows itself as an opportunity to answer to performance art hybrid temporalities. The theatre sees itself as an institution of the present, residential and for the presentation of contemporary works and that could, on a recurrent basis, build bridges, not only with research projects and scientific knowledge providing debate about new creations. This, however, will only be possible if the university-museum-theatre triad becomes a single place, where the archive and the repertory come together, where different voices are heard beside documents and records, promising future synergies that will feed each side of the knowledge triangle: theorising, materialisation and experimentation. That triangulation will also have repercussions regarding practices of preservation. This triad, as an operational concept, can respond to difficulties seen by every institution that aims preserving this manifestation of Cultural Heritage. In the same way, it allows for new possibilities in curating exhibitions as well as establishing dialogues between performative works of art and those with a more traditional format. History is then experienced in new ways, namely through the exhibition of non-conventional historical-artistic narratives and nonformal experimentation and learning processes. As practices of preservation are interconnected, the effective preservation of these artworks can happen... in practice. 


\section{References}

AADK. 2016. Reacting to time: the Portuguese in performance art. English version. http://www.aadkportugal.com/reacting-to-time-en/about/ $\quad$ (accessed on $13^{\text {th }}$ October 2016).

Auslander, Philip. 2006. "The Performativity of Performance Documentation". PAJ 84 $1-10$.

Austin, John L. 1965. How to Do Things with Words. Cambridge: Harvard University Press.

Bishop, Claire. 2012. Artificial Hells: Participatory Art and the Politics of Spectatorship, London: Verso.

Blackson, Robert. 2007. “Once More... With Feeling: Reenactment in Contemporary Art and Culture". Art Journal 66 (1): 28-40.

Calonje, Teresa. 2015. "Introduction". In Live Forever: Collecting Live Art, ed. T. Calonje, 11-26. London: Koenig Books.

Chalmers, Jessica. 2008. "Marina Abramović and the Reperformance of Authenticity". Journal of Dramatic Theory and Criticism, XXII (2): 23-40.

Derrida, Jacques. 1977 (1988). Limited Inc. Evanston, IL: Northwestern University Press.

Foster, Hal. 2015. Bad New Days: Art, Criticism, Emergency. London/ New York: Verso.

Goldberg, Roselee. 2001. Performance art: from futurism to the present, London: Thames \& Hudson.

Gurin, E. H. 1991. "Noodling around with Exhibiting Opportunities". In Exhibiting Cultures: The Poetics and Politics of Museum Display, edited by I. Karp and S. Lavine, 176-90. Washington, DC: Smithsonian Institution Press.

Harris, N. 1990. Cultural excursions: marketing appetites and cultural tastes in modern America. Chicago: Chicago University Press.

Hengel, Louis van den. 2017. "Archives of Affect: Performance, Reenactment and the Becoming of Memory". In Materializing Memory in Art and Popular Culture, ed. by L. Muntean, L.Plate, and A. Smelik, London and New York: Routledge: 125141.

Jones, Amelia. 1997. "“Presence" in Absentia: Experiencing Performance as Documentation". Art Journal, 56 (4): 11-18.

Jones, Amelia. 2012. "The Now and the Has Been: Paradoxes of Live Art in History". In Perform, Repeat, Record: Live Art in History ed. by A. Jones and A. Heathfield, Bristol: Intellect Lda, 9-25.

Kaprow, Allan. 1958 (1993). "The Legacy of Jackson Pollock". In Essays on the Blurring of Art and Life. Berkeley, CA: University of California Press: 1-9.

Laurenson, Pip, and Vivian van Saaze. 2014. "Collecting Performance-Based Art: New Challenges and Shifting Perspectives". In Performativity in the Gallery: Staging Interactive Encounters, edited by Outi Remes, Laura MacCulloch and Marika Leino, 27-41. Oxford: Peter Lang AG, Internationaler Verlag der Wissenschaften.

Lepecki, André. 2010. The Body as Archive: Will to Re-Enact and the Afterlives of Dances. Dance Research Journal, 42 (2), 28-48.

Lippard, Lucy. 1973. Six Years: The Dematerialization of the Art Object from 1966 to $1972 \ldots$... Berkeley and Los Angeles: University of California Press.

Madeira, Cláudia. 2007. O hibridismo nas artes performativas em Portugal. Unpublished PhD Thesis, Lisbon: Faculdade de Ciências Sociais e Humanas: Universidade 
Nova de Lisboa. Available at: http://hdl.handle.net/10451/322, accessed on $27^{\text {th }}$ October 2015.

Madeira, Cláudia. 2012. "The 'return of performance art from a global perspective", In Cadernos de Arte \& Antropologia, 1(2), 38-52. DOI : 10.4000/cadernosaa. 652

Madeira, Cláudia. 2016. "Transgenealogies of Portuguese Performance Art". Performance Research, Special issue On Trans/Performance, edited by Amelia Jones 21 (5), 37-46. DOI:10.1080/13528165.2016.1223446

Madeira, Cláudia. 2017. "The 'Performative' and 'Speculative' History of Portuguese Performance Art”, Revista de História da Arte - Série W, 6, Instituto de História da Arte (forthcoming).

Marçal, Hélia. 2017. "Conservation in an era of participation". Journal of the Institute of Conservation, 40 (2): 97-104. DOI: 10.1080/19455224.2017.1319872.

Marçal, Hélia. 2017. "Rites of passage: a conservator's perspective on the incorporation of performance artworks into museological collections", Revista de História da Arte - Série W, 6, Instituto de História da Arte (forthcoming).

Marçal, Hélia and Rita Macedo. 2017. "The aim of documentation: micro-decisions of the documentation process of performance-based artworks". In ICOM-CC $18^{\text {th }}$ Triennial Conference Preprints, Copenhagen, 4-8 September 2017, edited by J. Bridgland. Paris: International Council of Museums.

Marçal, Hélia, Andreia Nogueira, Rita Macedo. 2017. "Materializar o intangível: a documentação da obra Luís Vaz 73 (1975) de Ernesto de Sousa e Jorge Peixinho”, Conservar Património. (forthcoming) DOI: 10.14568/cp2016042

Phelan, Peggy. 1993. Unmarked: the politics of performance. London: Routledge.

Pieterse, Yan Nederveen. 1997. "Multiculturalism and Museums: Discourse about Others in the Age of Globalization". Theory, Culture \& Society 14: 123-146.

Rovisco, Vânia. 2016. Videoconference, personal communication to Hélia Marçal, $4^{\text {th }}$ October 2016.

Vall, Renée, Hanna Hölling, Tatja Scholte and Sanneke Stigter. 2011. "Reflections on a biographical approach to contemporary art conservation". In ICOM-CC $16^{\text {th }}$ Triennial Meeting Preprints, Lisbon, 19-23 September, edited by J. Bridgland. Almada: Critério.

Vieira, Ana Bigotte. "NO ALEPH. Notas a propósito de uma investigação sobre o Serviço ACARTE da Funda-ção Calouste Gulbenkian - 1984/1989”. Ler História, 67: 63-89.

Wheeler, Britta B. 2003. "The institutionalization of an American avant-garde: performance art as democratic culture, 1970-2000". Sociological Perspectives, 46 (4): 491-512.

\section{Biographies}

Cláudia Madeira is an Auxiliary Professor and Researcher at FCSH - NOVA University of Lisbon. Her post-doctoral research was entitled Social Art. Performative Art? (20092012) and was carried out at ICS-UL. She holds a doctorate in sociology for the same 
institute, for which she presented a thesis on Performing Arts Hybridity in Portugal (2007). She is the author of the books Hybrid. From myth to the new invasive paradigm? (Mundos Sociais, 2010) and New Dignitaries: The Cultural Programmers (Celta, 2002). She has also written a number of articles about new forms of hybridism and performativity in the arts.

Hélia Marçal (b. 1988) received her Master degree in Conservation and Restoration from Nova University of Lisboa (2012). She is now a $\mathrm{PhD}$ Candidate in the same University with a project funded by Fundação para a Ciência e Tecnologia. Her PhD project verses in the preservation of performance artworks focusing on a critical analysis of documentation strategies and in the study of decision-making in the conservation of these works. She has published several articles about conservation theory, contemporary art conservation, performance art conservation, and practices of conservation. After two years as Assistant Coordinator, since the 2016 she has been the Coordinator from Theory and History of Conservation Working Group of the International Council of Museums Committee for Conservation.

Daniela Salazar finished a degree in History and completed a MA in Museology in 2013, at in FCSH - NOVA University of Lisbon. She was researcher in the project of Association for the Study of Theatre and Performance in Portugal, funded by the Calouste Gulbenkian Foundation. Until 2015, she was responsible for managing the collection, the exhibition program and educational service plan of the newly created Sumol Museum, managed by the company SUMOL + COMPAL. Nowadays she is a $\mathrm{PhD}$ fellow and her project is about performativity in exhibition: the place of performance in curatorial context. 